\title{
Developing a Decision Support System for Evaluating an Investment in Fare Collection Systems in Transit
}

\author{
Parvis Ghandforoush, John Collura, and Valeri Plotnikov \\ Virginia Polytechnic Institute and State University
}

\begin{abstract}
This article presents the initial development of a decision support system (DSS) to assess cost impacts of upgrading or replacing a transit ticketing and fare collection (TFC) system. Assessment of these costs, typically, requires extensive calculations and involves estimation of unknown parameters such as future ridership growth rate, equipment utilization rate, and interest rate on debt financing. This DSS is developed with two categories of policy-and decision-makers in mind - transit agency managers and transit industry researchers and policy-makers.

With the aid of this DSS, a transit manager or analyst is able to specify current TFC system characteristics, select desirable options for a new TFC system, and in a matter of minutes estimate capital costs, forecast operating costs, perform net present value and payback period analyses for alternative TFC systems. This article also presents $a$ prototype TFC DSS including a model base, database, knowledge base, and the Microsoft Excel-based graphical user interface.
\end{abstract}




\section{Introduction}

The concept of decision support systems (DSS) evolved along with the development of computer systems in the 1950s and 1960s. With the advent of inexpensive and easy-to-use personal computers in the 1980s, DSS experienced further development and gained widespread acceptance. Today, DSS are a common tool for managers and other decision-makers in most areas of business, research, and science (Shim et al. 2002).

Being one of the major sectors of the U.S. economy, transportation was among the early adapters of computer technologies. As the use of computing resources in transportation continues to grow, more and more transportation operations and planning activities benefit from the aid of DSS.

Ticketing and fare collection (TFC) systems are one of the major elements of transit infrastructure and, thus, also require comprehensive assessment. Although new fare collection technologies offer increased flexibility in revenue collection, reliability of a TFC system, and convenience to transit riders, implementation of these technologies may require substantial investment on the part of a transit agency (Lovering and Ashmore 2000).

The DSS described in this article is intended to improve the decision-making process associated with upgrading or replacing a transit TFC system. More specifically, the proposed DSS should help a decision-maker to assess capital and operating costs of alternative TFC systems. With the aid of this DSS, a transit manager should be able to specify current TFC system characteristics, select desirable options for a new TFC system, and in a matter of minutes estimate capital costs, forecast operating costs, perform net present value and payback period analyses for alternative TFC systems.

The following section presents a general description of the purpose, structure, and functions of the proposed DSS. It is followed by a detailed description of each module of the DSS. The article concludes with a discussion of a prototype TFC DSS and a step-by-step example of using this DSS in the spreadsheet environment (Buehlmann, Ragsdale, and Gfeller 2000).

\section{General Description of the TFC DSS}

The composition of the TFC DSS is similar to that of a generic DSS and consists of four modules: graphical user interface (GUI), database (DB), model base (MB), and knowledge base (KB) (Beynon, Rasmequan, and Russ 2002). The structure and functions of the TFC DSS are illustrated in Figure 1 and further discussed below. 
Figure 1. Simulation-Optimization Hybrid Method

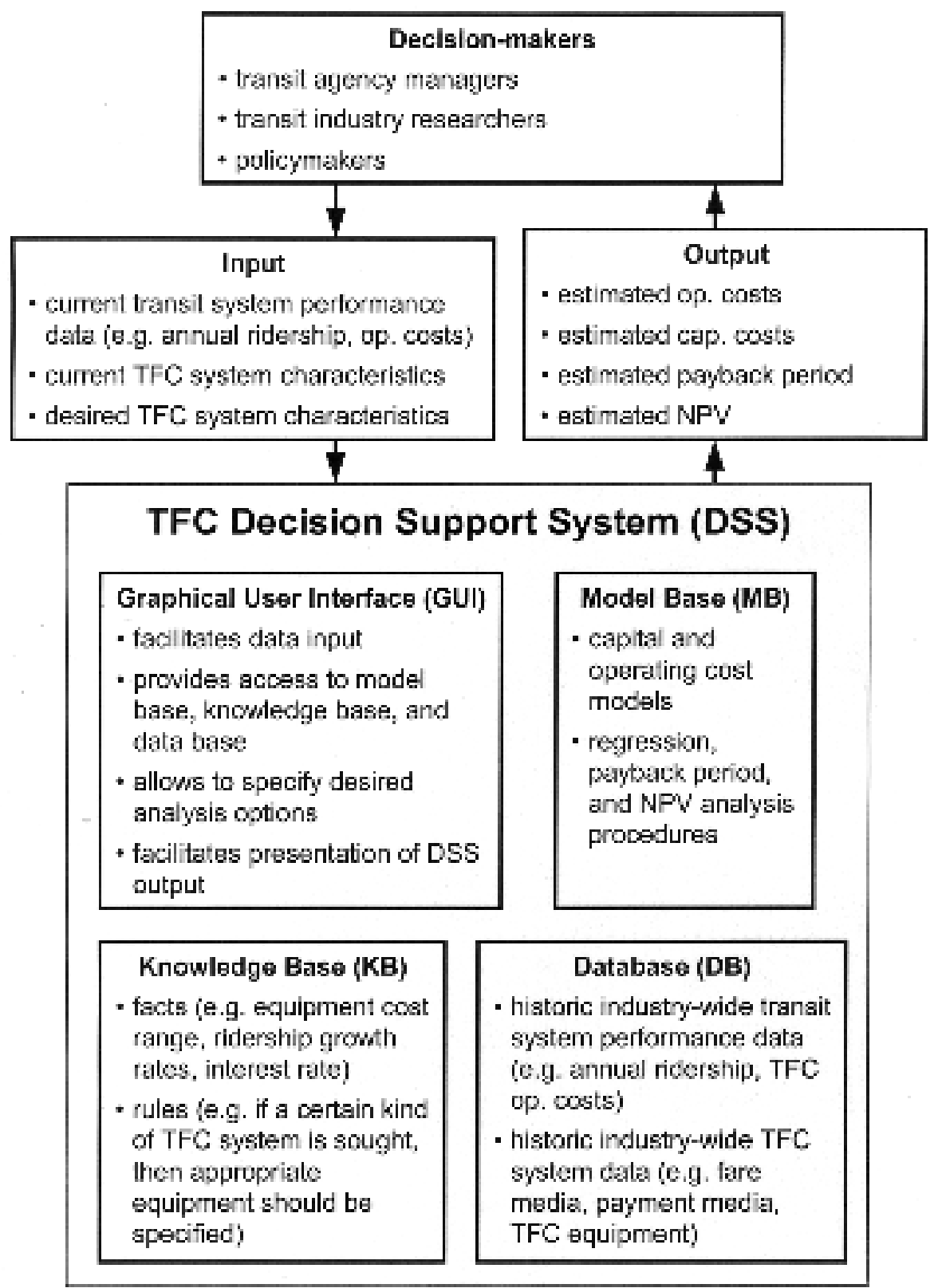


The TFC DSS is intended to aid in estimating capital costs, forecasting operating costs, performing net present value analysis, and conducting payback period analysis for alternative TFC systems. Consequently, there are two categories of policy-and decision-makers who can benefit from this DSS - transit agency managers and transit industry researchers and policy-makers.

On the transit agency level, management should find this DSS helpful in TFC budget planning, performing evaluation of TFC improvement projects, and assessment of alternative TFC technologies. The TFC DSS can provide a crude TFC budget estimate for several periods in advance based on a number of forecast variables such as ridership and TFC equipment utilization rates. It can also help in comparing cost effects of TFC improvement projects, although evaluation of such projects is likely to involve more than just a cost analysis. Finally, transit agency managers and planners can apply this DSS to assess the impact of individual TFC technologies on TFC operating costs (e.g., discontinuing the use of certain fare media such as tokens).

On the other hand, transit industry researchers and policy-makers from university transportation centers and organizations, such as the Volpe National Transportation Research Center, American Public Transit Association (APTA), and Federal Transit Administration (FTA), are also likely to find the TFC DSS useful in the following ways:

- to analyze performance of existing and new TFC technologies (as well as various combinations of these technologies) across the transit industry

- to analyze the effect of transit demand, transit mode, and other factors on costs of fare collection

- to determine trends and provide guidance in the development of fare collection systems on transit

As shown in Figure 1, the user of the TFC DSS will need to input three categories of data depending on the nature of the analysis requested. These categories of data include the current transit system performance data, current TFC system characteristics, and desired TFC system characteristics.

The current transit system performance data include transit ridership and TFC operating costs. These data are necessary to conduct various analyses on the transit agency level including TFC budget projections, evaluation of TFC improvement projects, and assessment of the impact of individual TFC technologies on TFC op- 
erating costs. Current transit system performance data are not required for industry-wide TFC system analyses since these analyses rely on historic data contained in the database module.

The current TFC system characteristics data include three types of payment media utilization rates (cash, checks, and credit cards), three types of fare media utilization rates (cash, nonelectronic, and electronic), and percent of fare media sold by machine. Again, input of these data is necessary to conduct analyses on the transit agency level since the industry-wide TFC system analyses rely on the historic data contained in the database module.

The desired TFC system characteristics data are of the same format as the current TFC system characteristics data allowing the user to specify the payment and fare media utilization rates, and percent of fare media sold by machine. These data are necessary to conduct analyses on the transit agency level as well as for industrywide TFC system analyses.

The output of the TFC DSS includes graphs and numeric results relating to estimation of capital and operating costs as well as graphs and numeric results relating to payback period and net present value analyses of alternative TFC systems.

The following sections describe each module of the proposed DSS in greater detail.

\section{Model Base}

The purpose of the model base module is to store mathematical equations describing relationships between variables and to execute programmatic procedures that perform various types of analyses. The mathematical models and procedures contained in this module include:

- a model describing the impact of transit demand, transit mode, and TFC technologies on TFC operating costs

- a model for calculating capital costs of alternative TFC systems

- a model for conducting payback period analysis that determines how quickly the investment in a new TFC system can be offset by reductions in operating costs associated with the new TFC system

- a model for conducting a net present value analysis that compares capital costs of a new TFC system to reductions in operating costs associated with this system over a certain period of time and takes into account discount and growth rates of the future cash flows 
- programmatic procedures to access spreadsheet software's built-in tools to perform various statistical analyses

\section{TFC Operating Cost Model}

As reported by Plotnikov (2001), TFC operating costs (OC) are influenced by a number of factors including transit system demand, TFC and transit system technologies, labor rules, and fare policy.

$$
T F C O C=f\left(x_{i}\right)
$$

where:

$$
\begin{array}{ll}
\mathrm{x}_{1} & \text { is transit demand (ridership) } \\
\mathrm{x}_{2} & \text { represents transit technology (mode) } \\
\mathrm{x}_{3} & \text { equals TFC technology } \\
\mathrm{x}_{4} & \text { is fare policy } \\
\mathrm{x}_{5} & \text { represents labor rules }
\end{array}
$$

Furthermore, Plotnikov (2001) concludes that TFC OC can be estimated based on the transit system demand, transit mode, and TFC System Technology Index (TFCSTI) - a variable that describes components of a TFC system.

$$
y_{1}=b_{0}+b_{1} x_{1}+b_{2} x_{2}+b_{3} x_{3}
$$

where:

$$
\begin{array}{ll}
\mathrm{y}_{1} & \text { equals TFC OC } \\
\mathrm{x}_{1} & \text { represents transit demand (ridership) } \\
\mathrm{x}_{2} & \text { is transit technology (mode) } \\
\mathrm{x}_{3} & \text { equals TFCSTI }
\end{array}
$$

Plotnikov (2001) also presents the structure of the TFCSTI. The index is a weighted sum of scores associated with TFC technology groups (TG) comprising a certain TFC system and can be computed as:

$$
\text { TFCSTI }=W_{1} * S_{P M}+W_{2} * S_{F M}+W_{3}^{*} S_{E Q}
$$


where:

TFCSTI
$\mathrm{S}_{\mathrm{PM}}$
$\mathrm{S}_{\mathrm{FM}}$
$\mathrm{S}_{\mathrm{EQ}}$
$\mathrm{W}_{1}, \mathrm{~W}_{2}, \mathrm{~W}_{3}$

is TFCSTI

represents payment media TFC TG score

equals fare media TFC TG score is equipment TFC TG score are coefficients (weights) reflecting the relative impact of fare media, payment media, and TFC equipment on a certain aspect of a TFC system performance.

As formulated by Plotnikov (2001), a TFC TG score represents the impact of a group of similar TFC technologies on a particular aspect of TFC system performance (in this case TFC OC). A TFC TG score is computed as a sum of products of utilization rates and weights associated with individual TFC technologies within their group.

$$
\text { TFC TG }=w_{1}^{*} t_{1}+w_{2}^{*} t_{2}+\ldots+w_{i}^{*} t_{i}
$$

where:

$\begin{array}{ll}\text { TFC TG } & \text { is TFC technology group (e.g. fare media) score } \\ \mathrm{t}_{1}, \mathrm{t}_{2}, \ldots, \mathrm{t}_{\mathrm{i}} & \text { represents technology utilization rates } \\ \mathrm{w}_{1}, \mathrm{w}_{2}, \ldots, \mathrm{w}_{\mathrm{i}} & \text { are individual TFC technology weights }\end{array}$

Due to lack of comprehensive and uniform data on transit TFC systems in the United States, Plotnikov (2001) recommends the following variables to describe TFC systems: payment media utilization rates (expressed as percent of the total fare revenue paid with cash, checks, and credit cards), fare media utilization rates (expressed as percent of the total fare revenue collected with cash, nonelectronic fare media, and electronic fare media), and percent of fare media sold by machines. Once all these variables are specified, individual technology weights, TFC TG scores, and TFC TG weights can be estimated with the aid of regression analysis. 
Finally, TFC OC can be forecast based on the specified values of transit demand, transit mode, TFCSTI, and coefficients obtained form regression analysis. The transit demand is measured in unlinked passenger trips (UPT), whereas transit mode is a dummy variable that assumes a value of 0 (for motorbus mode), or 1 (for heavy rail mode).

\section{TFC Capital Cost Model}

The TFC Capital Cost Model is designed to facilitate the evaluation of cost impacts of investing in an electronic TFC system as opposed to continue using a nonelectronic TFC system. The model should help the user to obtain a crude estimate of investing into a new (magnetic stripe or smart card) system based on the three types of variables:

- range of TFC system capabilities desired and type of TFC equipment necessary to provide these capabilities

- quantity of the equipment required for a given system, and

- unit price of equipment selected

The general form of the capital cost model is presented in equation 5 (Booz-Allen \& Hamilton, Inc. 2000).

$$
T C C=\left[\left(£ U C_{i}^{*} q_{i}\right) *\left(1+x_{P S}+x_{I C}+x_{E S P M}\right)\right] *\left(1+y_{C}\right)
$$

where:

$$
\begin{array}{ll}
\mathrm{TCC} & \begin{array}{l}
\text { represents total capital costs } \\
\mathrm{UC}_{\mathrm{i}}
\end{array} \\
\mathrm{q}_{\mathrm{i}} & \begin{array}{l}
\text { is the unit cost of TFC equipment } i \\
\mathrm{x}_{\mathrm{PS}}
\end{array} \\
\begin{array}{l}
\text { are nonrecurring parts and services costs expressed as percent of } \\
\text { the equipment costs }
\end{array} \\
\mathrm{x}_{\mathrm{IC}} & \begin{array}{l}
\text { are nonrecurring installation and construction costs expressed as } \\
\text { percent of the equipment costs }
\end{array} \\
\mathrm{x}_{\mathrm{ESPM}} & \begin{array}{l}
\text { equals nonrecurring engineering, software, and project manage- } \\
\text { ment costs expressed as percent of the equipment costs }
\end{array} \\
\mathrm{y}_{\mathrm{C}} & \begin{array}{l}
\text { represents contingency costs }
\end{array}
\end{array}
$$

To utilize the TFC Capital Cost Model, the user first needs to select the desired capabilities of the new TFC system through the GUI module. For example, the user may seek the capability of integrating the agency's fare collection system with other 
transit systems in the region. Next, the user accesses the KB module and specifies the TFC equipment options associated with the desired TFC system capabilities. In the previous example, the user would be required to select smart card fare media and appropriate smart card readers. For each type of TFC equipment, the user enters the quantity of the equipment needed based on the mode, size, and other characteristics of the transit systems. The KB module will assist the user by providing logical cues and ranges of values to ensure that the parameters entered are sensible. For example, the user can be advised to estimate the initial number of smart cards required based on the percentage of the number of unique transit system riders and the number of smart card readers based on the number of vehicles operated in maximum service. Finally, the user can change default values of unit costs corresponding to the equipment selected. The KB module is evoked to provide estimates of TFC equipment unit costs as well as the likely ranges for these values.

Once all types of the required TFC equipment, their quantity, and unit costs are specified, the procedure based on equation 5 is run and the user obtains an estimate of the total capital costs associated with a new TFC system. This estimate can be subsequently used to perform payback period and net present value analyses.

\section{Payback Period Analysis}

Although the TFC Operating Cost Model and TFC Capital Cost Models can be used separately to estimate operating and capital costs associated with different types of transit TFC systems, they can also be used together to perform payback period analysis or calculate the net present value of a certain investment project. Payback period analysis can be used to evaluate how quickly the investment into a new TFC system can be recovered based on the savings in OC associated with the use of new TFC technologies. The formula for payback period analysis is presented in equation 6 (Ross, Westerfield, and Jaffe 1996).

$$
x=T C C /\left(T F C O C_{E}-T F C O C_{N}\right)
$$

where:

$\mathrm{X}$

TCC

TFC OC $\mathrm{TFC} \mathrm{OC}_{\mathrm{N}}$ equals payback period is total capital costs represents TFC OC of the existing system represents TFC OC of the new system 
To perform payback period analysis, the user needs to specify all the parameters required for calculating:

- OC of the existing TFC system

- OC of the new TFC system

- capital costs of the new TFC system

\section{Net Present Value Analysis}

Net present value analysis shows whether the investment in a new TFC system can be recovered based on the savings in OC associated with the use of this system over a specified period of time. Unlike payback period analysis, net present value analysis takes into account the discount rate on the future cash flows as well as the potential growth rate of future cash flows. The formula for net present value analysis is presented in equation 7 (Ross, Westerfield, and Jaffe 1996).

$N P V=-T C C+\left(T F C O C_{E}-T F C O C_{N}\right) *\left[\frac{1}{(\boldsymbol{r}-\boldsymbol{g})}-\frac{\boldsymbol{1}}{(\boldsymbol{r}-\boldsymbol{g})} \times\left(\frac{\boldsymbol{1}+\boldsymbol{g}}{\boldsymbol{1}+\boldsymbol{r}}\right)^{\boldsymbol{T}}\right]$

where:

$\begin{array}{ll}\text { NPV } & \text { is net present value } \\ \text { TCC } & \text { equals total capital costs } \\ \text { TFC OC }_{\mathrm{E}} & \text { reflects TFC OC of the existing system } \\ \text { TFC OC }_{\mathrm{N}} & \text { equals TFC OC of the new system } \\ \mathrm{r} & \text { is the discount rate } \\ \mathrm{g} & \text { is the rate of transit ridership growth } \\ \mathrm{T} & \text { represents number of periods }\end{array}$

To perform net present value analysis the user specifies all the parameters required for calculating: (a) OC of the existing TFC system, (b) OC of the new TFC system, (c) capital costs of the new TFC system, as well as the discount rate of the future cash flows and transit ridership growth rate. 


\section{Access to Spreadsheet Software Built-in Tools}

In addition to the models described above, the model base module contains programmatic procedures that allow the user to access the spreadsheet software builtin multiple regression and optimization tools to perform regression and risk analyses. When the user runs the TFC Operating Cost model in the Microsoft Excel environment, the multiple regression tool from the Data Analysis Plus add-in component is evoked. Similarly, the user can access Excel's Solver add-in component to perform risk analysis with the TFC Capital Cost model, payback period, and NPV analyses. Then, the user can specify the objective function (e.g., total capital costs or payback period), define variable parameters (e.g., equipment unit costs), set the constraints (e.g., quantities of TFC equipment), and evaluate different investment scenarios and outcomes.

\section{Database}

The database (DB) of the proposed DSS consists of operational and financial data on selected transit agencies in the United States as well as data describing transit TFC systems. These data are used to assess the strength of relationship between a dependent variable (TFC OC) and a set of independent variables (transit demand, transit mode, and TFCSTI) formulated in the model base module. Based on the nature and strength of this relationship, future operating cost of a desired or existing TFC system can be forecast.

The transit operational and financial data include transit agency ID, fiscal year, transit mode, transit demand, and annual TFC OC, and can be obtained from the National Transit Database (NTD). The transit TFC system data include payment media utilization rates (expressed as percent of the total fare revenue paid with cash, checks, and credit cards), fare media utilization rates (expressed as percent of the total fare revenue collected with cash, nonelectronic fare media, and electronic fare media), and percent of fare media sold by machines. Since, currently, there is no reliable source of the specified transit TFC system data available, these data should be obtained directly from transit agencies as described by Collura and Plotnikov (2001).

Tables 1 and 2 present the initial database of the proposed DSS. They build upon the data obtained from a survey of transit agencies conducted by Plotnikov (2001) (numbers in bold typeface denote estimated values). The initial database includes data entries on 15 bus and 9 heavy rail systems for the 1993 and 1998 fiscal years. The database can be accessed, modified, and populated via the GUI module. 


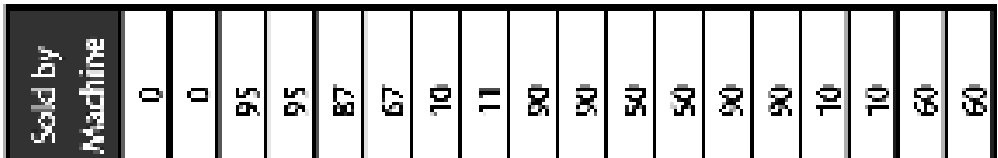

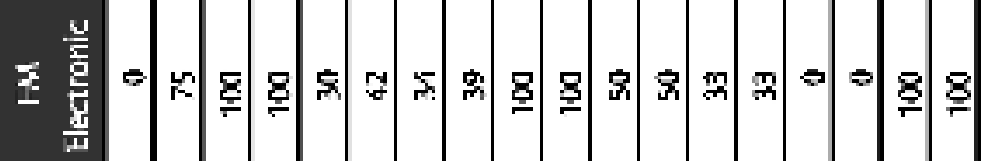

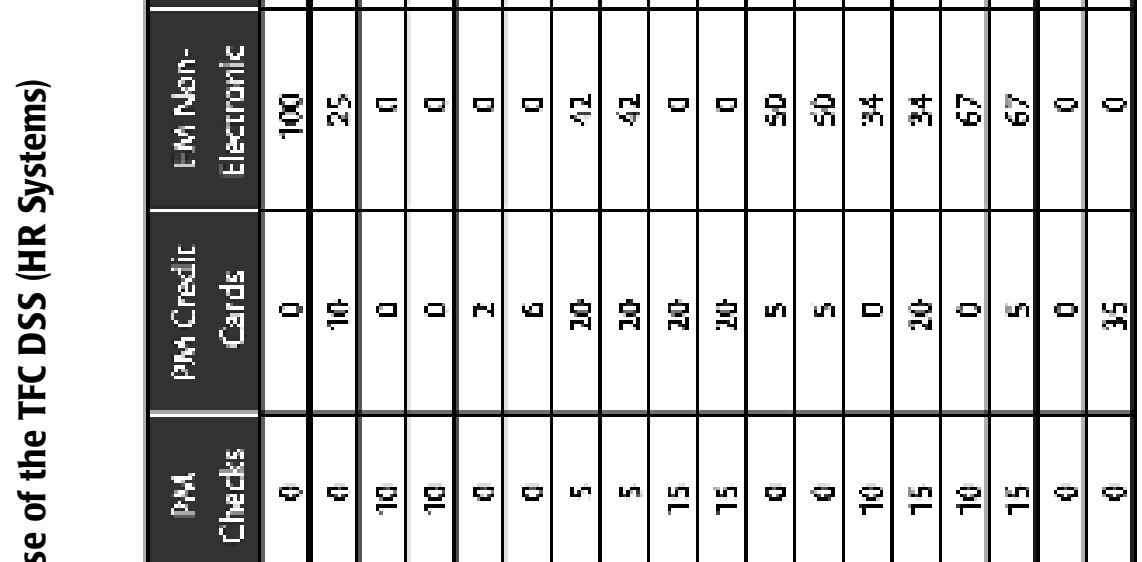

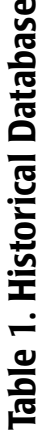

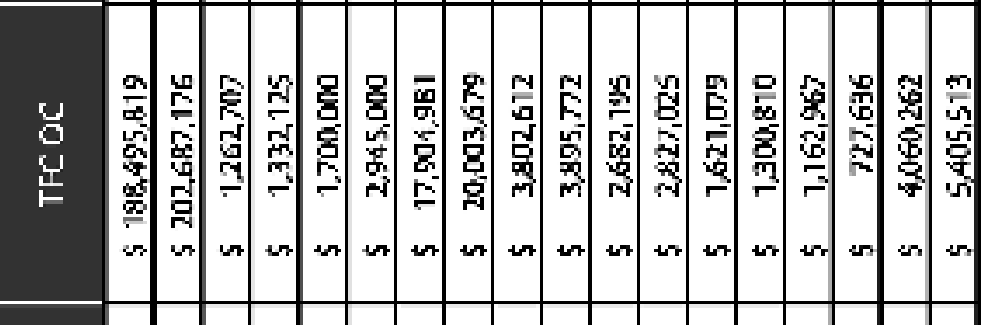

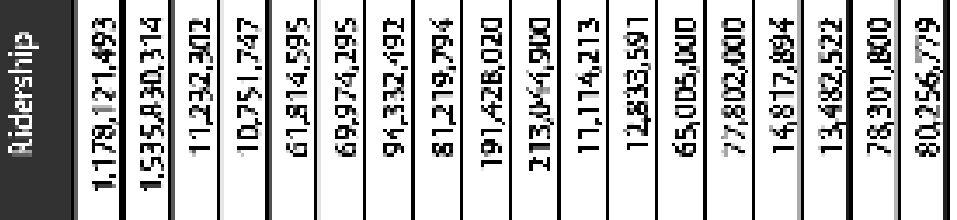

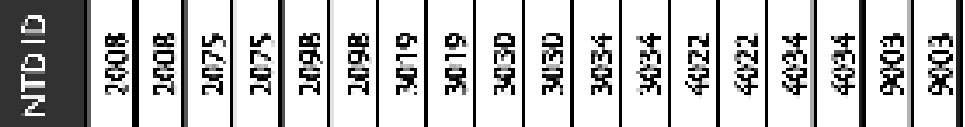

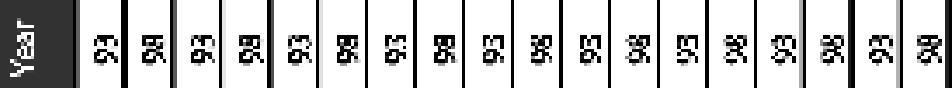




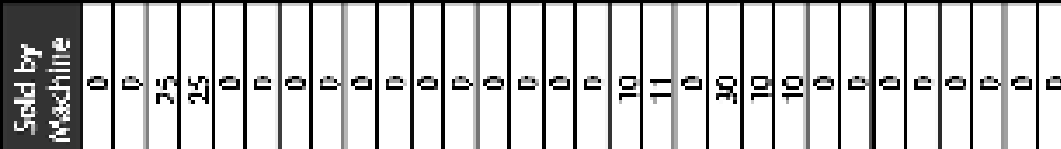

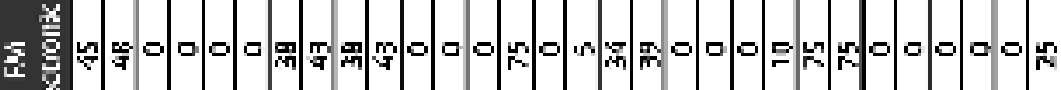
采

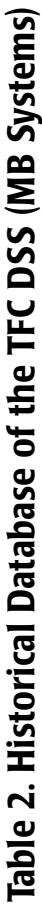

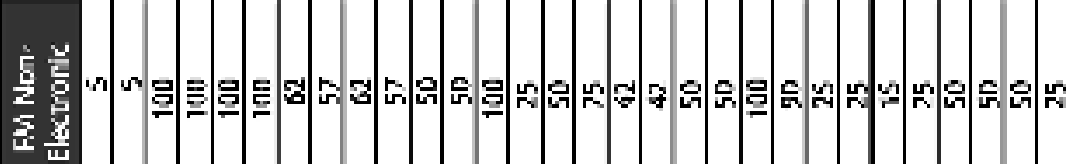

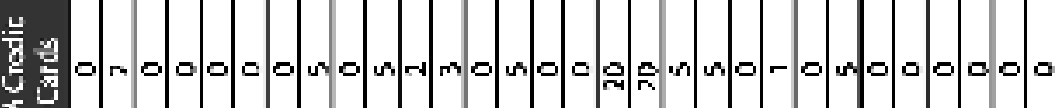
案

年

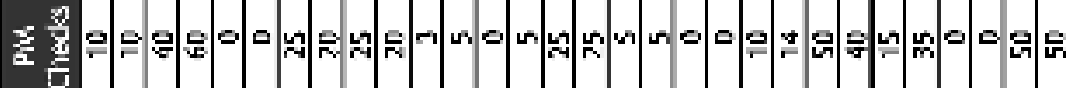

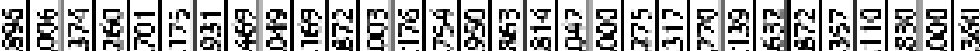

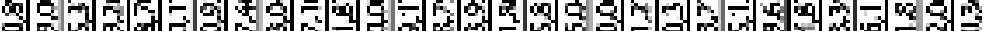

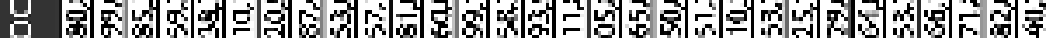

U

尼

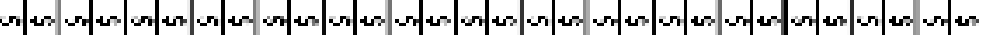

권

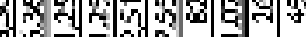




\section{Knowledge Base}

The knowledge base (KB) of the TFC DSS consists of problem-specific rules and facts relating to a particular transit system, TFC technology, or investment scenario. Information contained in the KB can be grouped in the following categories:

- TFC equipment unit cost averages and ranges

- ridership growth and interest rate averages and ranges

- quantity of TFC equipment selection rules

- type of TFC equipment selection rules

The TFC equipment unit cost averages and ranges support the user information needs for estimating capital costs of a new TFC system. As indicated in [5], the unit cost and quantity of TFC equipment are the major determinants of the total capital costs of a TFC system. Therefore, it is important to provide the user with cost estimates that are as close to those that could be found in the marketplace as possible. In some cases, the user might already have cost quotes on selected types of TFC equipment directly from a vendor or a system integrator in which case the $K B$ information can be used to verify the reasonableness of vendor quotes. Since the TFC equipment unit cost information is time sensitive, it will need to be updated periodically, perhaps, on a biannual basis.

Table 3 presents TFC equipment cost averages and ranges included into the KB module. These numbers are based on the estimates presented to the Greater Washington region transit operators by Booz-Allen \& Hamilton, Inc. in 2000.

Another category of the KB information is the ridership growth and interest rate averages and ranges. These rates are necessary to perform net present value analysis of TFC system alternatives. As discussed above, net present value analysis shows whether the investment in a new TFC system can be recovered based on the savings in OC associated with this system over a specified period of time. It takes into account the discount rate on the future cash flows as well as the potential growth rate of future cash flows. In this analysis, the discount rate reflects the cost of borrowing capital invested into the new TFC system and would generally depend on the state of the U.S. economy. In turn, since the investment in a new TFC system is expected to be recovered based on the savings in $O C$ associated with this system and since future TFC OC are forecast based on the future ridership, the growth 


\section{Table 3. TFC Equipment Cost Averages and Ranges}

\begin{tabular}{|c|c|c|c|}
\hline Thpe af Equipmert & Aмcrage & $\begin{array}{c}\text { Low } \\
\text { Etimace }\end{array}$ & $\begin{array}{c}\text { High } \\
\text { Estlmate }\end{array}$ \\
\hline Eus miagnelis lickel provessur (bland aluxie) & s $\quad 6500$ & $\$ 1,000$ & \$ 9000 \\
\hline Dus smarc card processor (stend alane) & 5 S, BDeO & 54,400 & 37200 \\
\hline Magetic scripe card (bre life) & $5 \quad 0.20$ & $5 \quad 0,10$ & 0.30 \\
\hline Mapretic sorpe card (1 or 2 uses) & $5 \quad 0.02$ & 0.02 & 0.02 \\
\hline Smart and & 9 & 3 & 15 \\
\hline Tirket worwling marhins: & 555000 & 545,010 & $\$ 65$, ann \\
\hline TVM - additional cosc for mapecic stripe proxessing & $5 \quad 5,000$ & $5 \quad 5,000$ & $5 \quad 5,000$ \\
\hline TViW - additional cost for amart cand processing & $\mathrm{S} 3,000$ & $\$ 3,000$ & $\$ 3,000$ \\
\hline Smart and iniciation desice & $\$ 12.500$ & \$ 14toull & \$ 15 , allu \\
\hline Poinc of sale derice for magerctk stipe card & 57.500 & $5 \quad 5.500$ & \$ HDODD \\
\hline Poinc of sale device to rectiarge smart card & $\$ \quad 4,250$ & $\$ 2,500$ & $\$ 6,000$ \\
\hline Stand alane validarar for masnetic strize cand & $\$ 13.500$ & S 10,000 & S 1,000 \\
\hline Stand alane valikdamor fror anare card & $5 \quad 6,5 \pi 0$ & $5 \quad 5, \Gamma \times O$ & $\$ 2,000$ \\
\hline Hand-held devke to read smart card & $5 \quad 4,250$ & $5 \quad 2,500$ & 56,000 \\
\hline Farebox with smart and reader & \$ $13,75 n$ & $\$ 11000$ & $\$ 16,500$ \\
\hline Garage data system & $\$ 35,730$ & $\$ 77,0$ dII & \$ 74,5116 \\
\hline Hownue collectlon waulcs & 521350 & 514,100 & 528.600 \\
\hline Mobile bins & $\$ 11,000$ & $\$ 8,000$ & 513,200 \\
\hline Mancy room equipment & $\$ 16.500$ & s 11,0an & 522,000 \\
\hline Inimalixing devicn & 512,300 & 511 1t,0nח & $515,0 n n$ \\
\hline Cenurad dala syscem & 54,000 & $53 \mathrm{~B}, 500$ & 549,500 \\
\hline Smart ard reacher & $\$ \quad 5,775$ & 54,400 & $\$ 7,150$ \\
\hline Data reporting symem & $\$ 16,500$ & $\$ 11,000$ & $\$ 22,000$ \\
\hline
\end{tabular}

rate of future cash flows reflects potential increase or decrease in transit ridership for the given system.

Nominal interest rates (based on three-month Treasury Bills) for the United States over the last two decades varied from about 15 percent in the early 1980 s to about 3 percent in early 1990s with the average about 6 to 7 percent. Therefore, the range of interest rates that the user can specify via the $K B$ module is between 3 and 15 percent with the default value of 6 percent.

The transit system ridership data included in the database indicate that average annual ridership growth rates for heavy rail systems for the period 1993 through 1998 varied from -2.95 percent to 5.45 percent with the median value of 2.16 percent. For the motorbus systems, this statistic varied between -4.24 percent and 11.12 percent with the median value of -1.18 percent. Consequently, the range of ridership growth rates that the user can specify via the $K B$ module is between -5.0 and 12.0 percent with the default value of 1.0 percent. 
The next category of the KB information contains rules for sele cting proper quantities of equipment for a new TFC system. As with the TFC equipment unit cost information, these rules should help the user calculate a gross estimate of the total capital costs associated with a new TFC system. Ultimately, equipment needs and unit costs will depend on the specific functionalities and configuration of a new TFC system as well as the vendor and specific equipment options selected. Table 4 presents allocation parameters for estimating quantities of different types of TFC equipment.

The last category of the KB information contains rules for selecting the proper type of equipment for specified TFC system capabilities. Based on these rules, the user is advised whether a magnetic stripe or a smart card TFC system is required. The TFC equipment selection rules contained in the KB are illustrated in Table 5.

\section{Table 4. TFC Equipment Allocation Parameters}

\begin{tabular}{|c|c|}
\hline Type of Equiprnent & Nlocation Parmerr \\
\hline Mapncpic srripe card /lone lifs) & Annuाal ridemship \\
\hline Magnetic stripe card (1 ar 2 use? & annusal ribership \\
\hline smatcand & annueal ridership \\
\hline Srmart card initiation device & apencoor \\
\hline Hevenue collection vauks & operacor \\
\hline Milobile birs & apanmr \\
\hline Money room equomenc & operacor \\
\hline Initializing device & apernar \\
\hline Central dara systein & optrabor \\
\hline Dan reporring system & aparam \\
\hline Garape daca syslem & parage \\
\hline Tidoss vending maxhine: & scarion \\
\hline Puiril of sale devike for maungsic slripe card & blalival \\
\hline Prine of sale devike no vextharge amaxt and & starrion \\
\hline Sand alone validator for masnetic syipu ard & station \\
\hline Sand alone valdaco for smart card & scartom \\
\hline Bus magnecic ticket procosor (stand akrne) & whicke \\
\hline Bus jmarr cand processor (scrand alone) & whikle \\
\hline lland-held device to read smart and & rehicle \\
\hline Farebox wich smain card reader & whikle \\
\hline Smart ard reader & vehick \\
\hline
\end{tabular}


Table 5. TFC Equipment Selection Rules

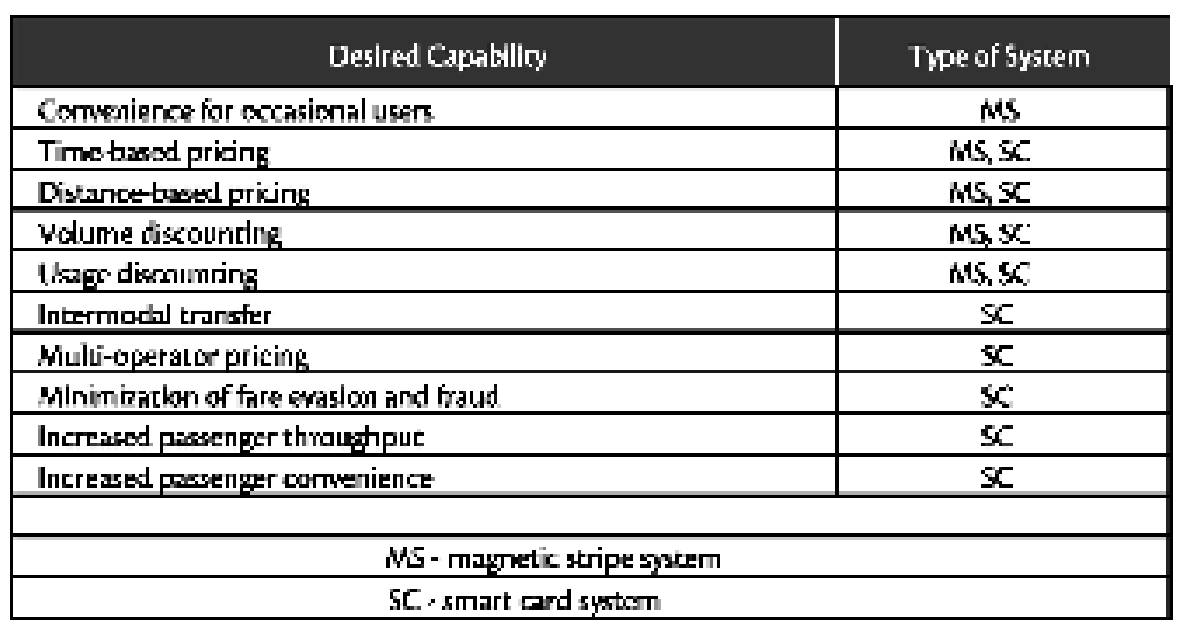

\section{Graphical User Interface}

The GUI of the TFC DSS features five main screens: TFC DSS Front screen, OC Analysis screen, Capital Cost Analysis screen, Payback Period Analysis screen, and Net Present Value Analysis screen. These GUI screens are presented in Figures 3 through 6 and are briefly described below.

The TFC DSS Front screen (see Figure 2) is the starting point of the TFC DSS. This screen allows the user to input the current transit system performance characteristics and specify existing and desirable TFC system parameters. This screen also offers the user links to the OC Analysis, Capital Cost Analysis, Payback Period Analysis, and Net Present Value Analysis screens.

The TFC OC Analysis screen (see Figure 3) presents forecasts of the existing and new (desired) TFC system OC for the near future in tabular and graphical formats. These forecasts are based on the parameters specified in the front screen of the DSS. The OC Analysis screen also provides links to access historical databases for heavy rail and motorbus modes. 


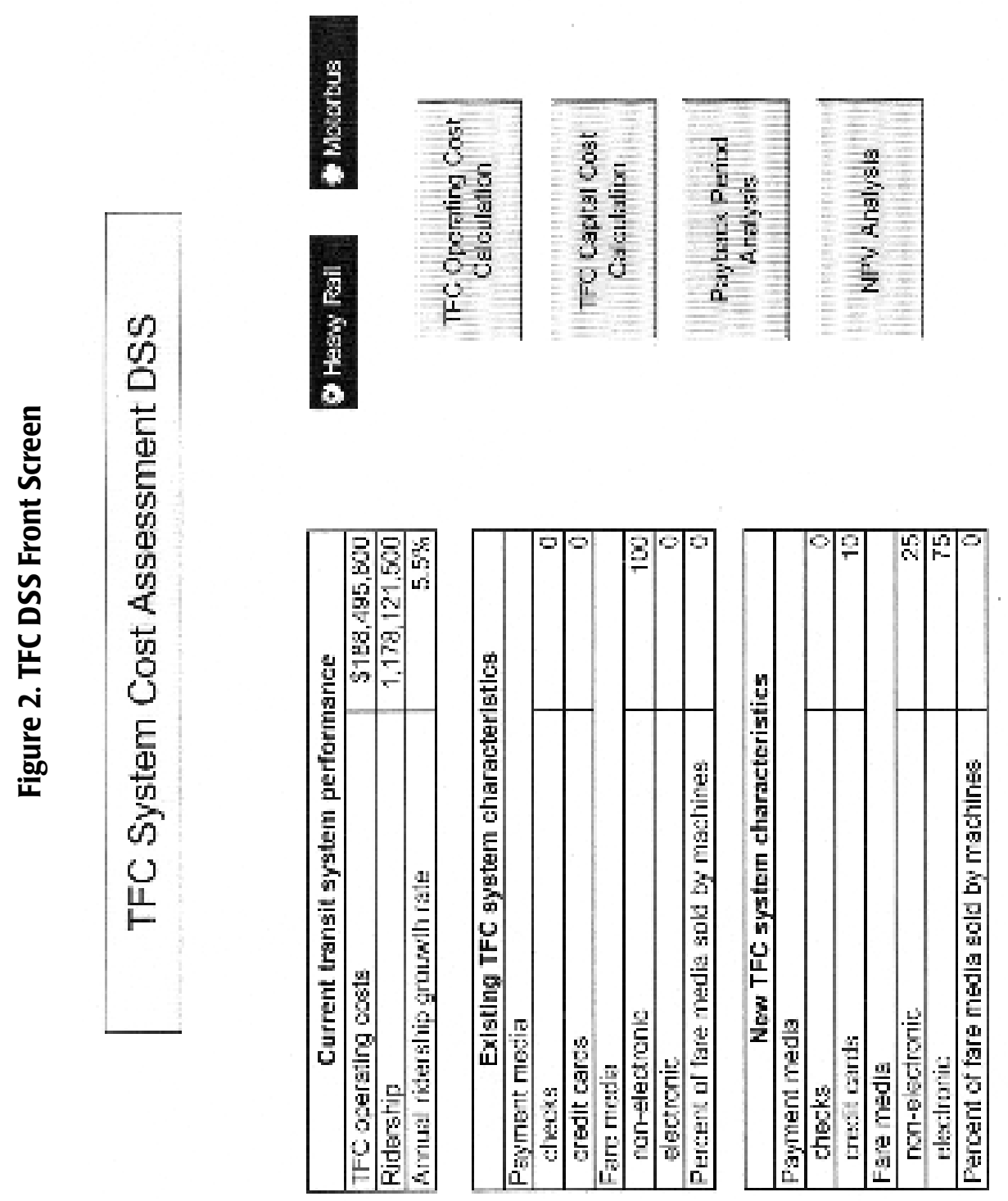



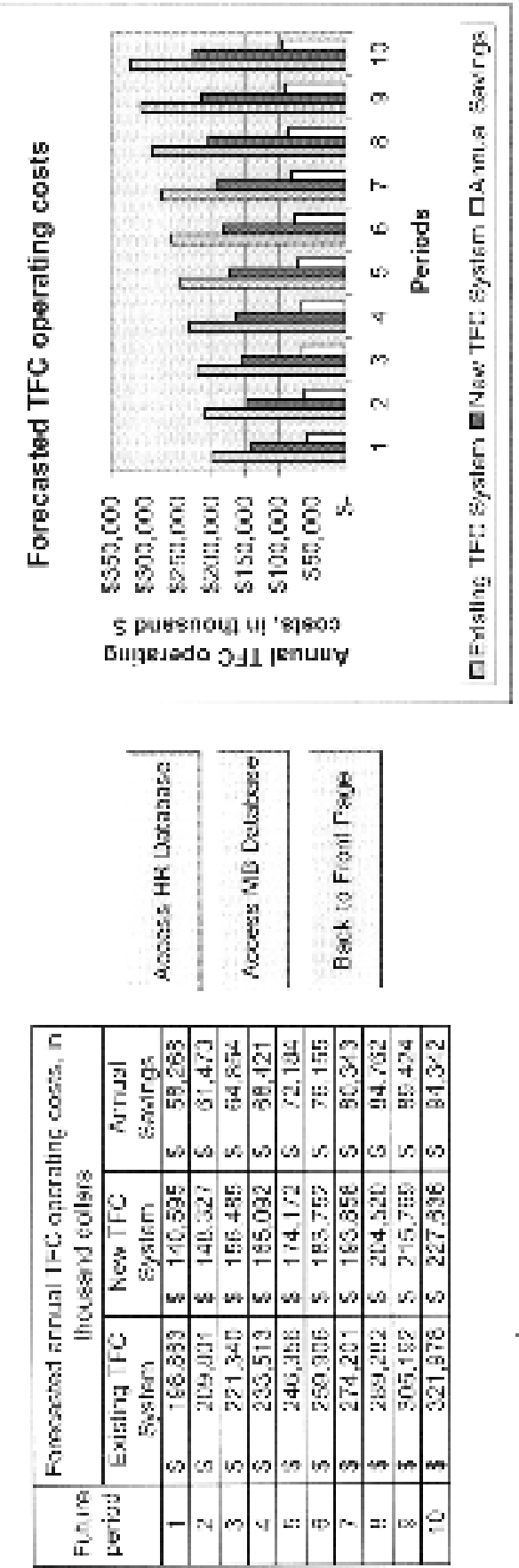


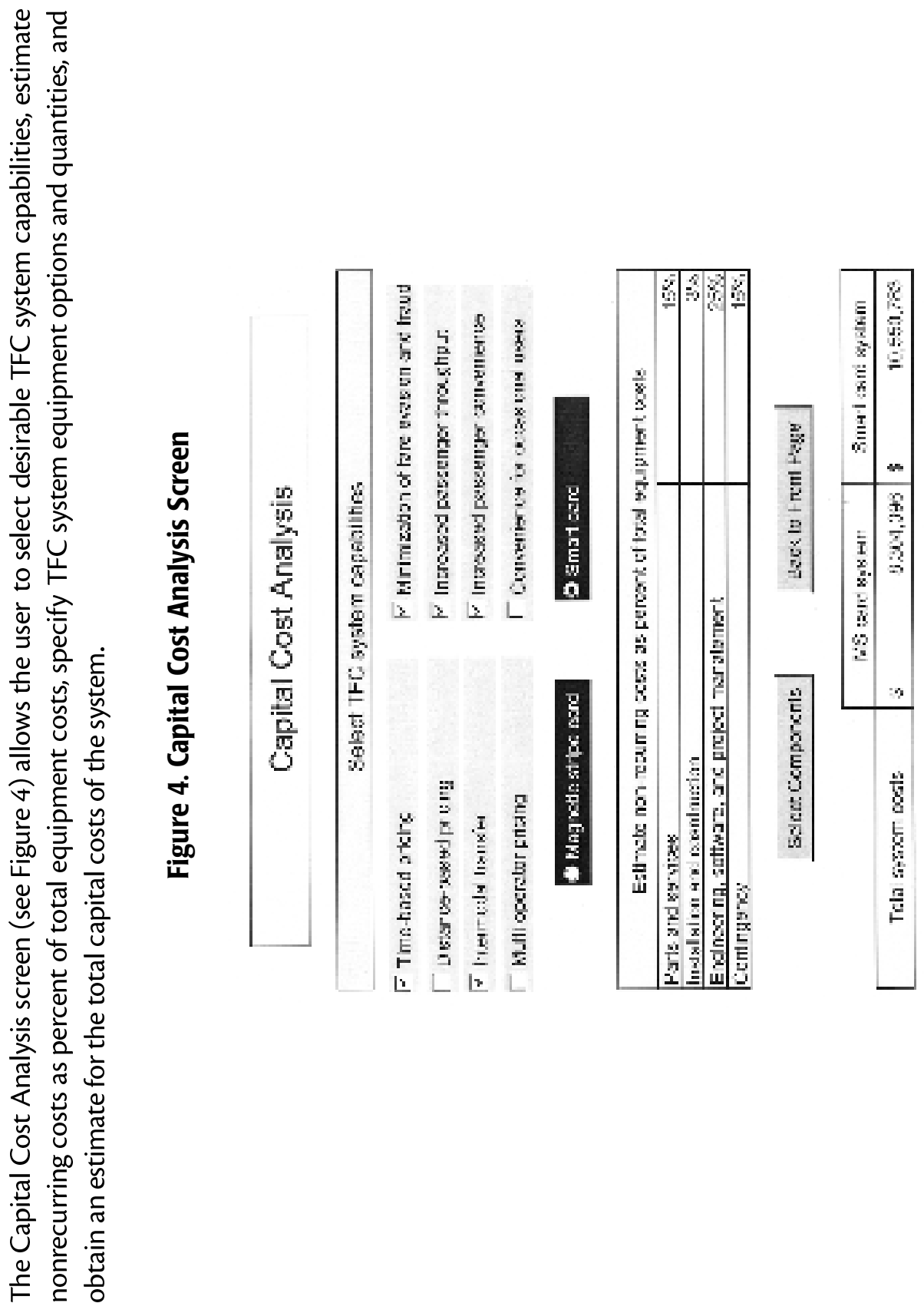



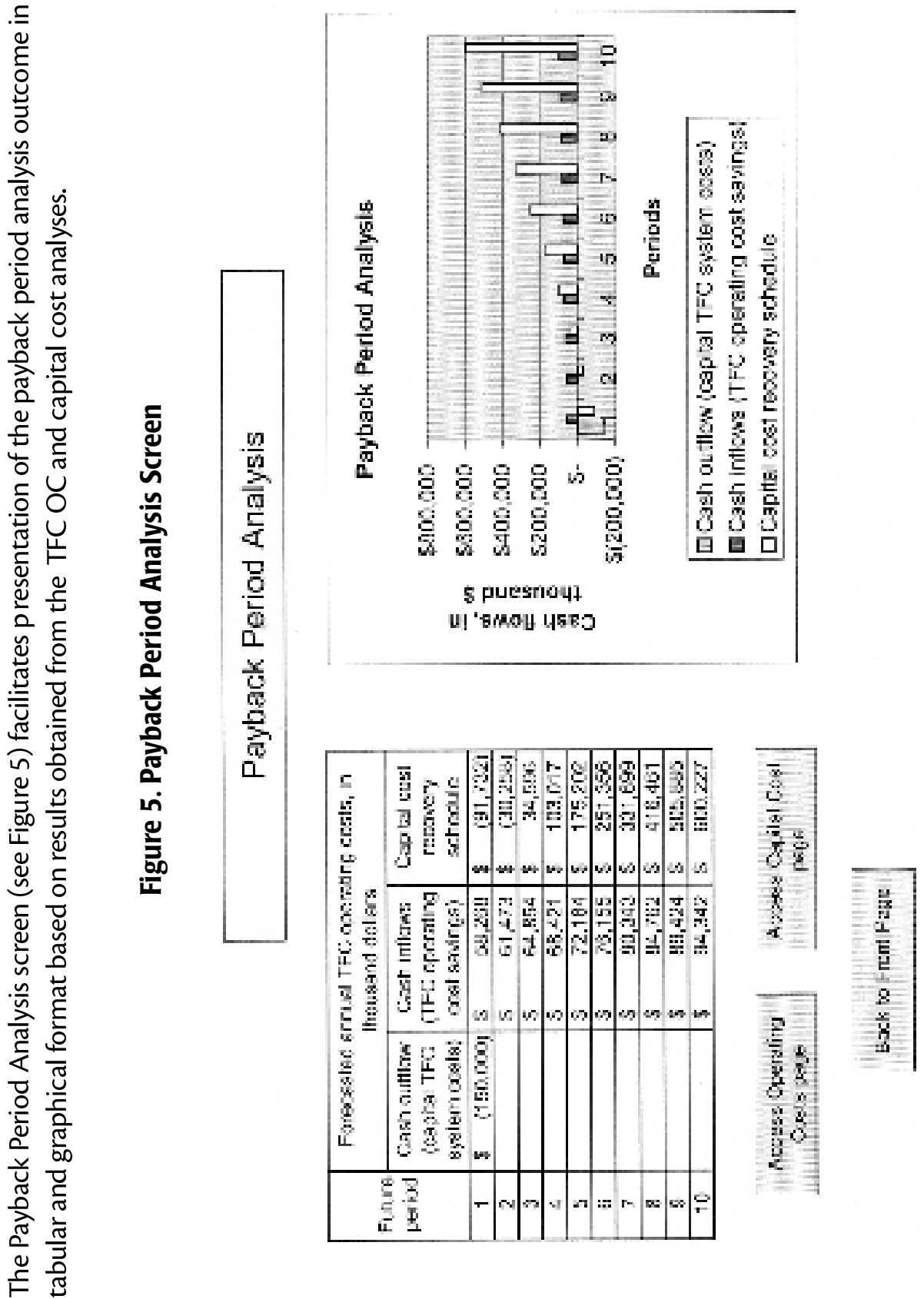
Finally, the Net Present Value Analysis screen (see Figure 6) shows results of the net present value analysis.

Figure 6. Net Present Value Analysis Screen

\section{Net Present Value Analysis}

\begin{tabular}{|l|r|}
\hline \multicolumn{2}{|c|}{ Specify NPV analysis parameters } \\
\hline Discounl rate \% $\%$ & $7 \%$ \\
\hline Forecast horizon, years & 5 \\
\hline
\end{tabular}

Specify TFC system capilal cost:s

Nel Prosert Value $\quad \$ \quad 114,754,788$

Eack to Front Paye 


\section{Summary, Conclusions, and Recommendations for Future Research}

This article presents the development of a DSS to assess cost impacts of upgrading or replacing a transit TFC system. This DSS is built with two categories of policyand decision-makers in mind-transit agency managers and transit industry researchers and policy-makers. On the transit agency level, management should find this decision support system helpful in TFC budget planning, performing evaluation of TFC improvement projects, and assessment of alternative TFC technologies. Transit industry researchers and policy-makers are also likely to find the TFC DSS useful in:

- analyzing performance of existing and new TFC technologies (as well as various combinations of these technologies) across the transit industry,

- analyzing the effect of transit demand, transit mode, and other factors on costs of fare collection, and

- determining trends and providing guidance in the development of fare collection systems on transit.

Although the major focus of this article is on a conceptual framework for financial analysis of TFC system performance, the article also provides details and specifics on the implementation of the TFC DSS in the spreadsheet software environment. To ensure the applicability of the TFC DSS as well as accuracy and precision of its forecasts, the database used in the DSS needs to be expanded and enhanced. Furthermore, it would be desirable to fine-tune the TFC DSS with reliable time-series data from individual transit agencies. 


\section{References}

APTA. 1999. 1999 Transit Fare Summary. American Public Transportation Association. Washington, DC.

APTA. 2001. Public Transportation Fact Book. American Public Transportation Association. Washington, DC.

Beynon, M., S. Rasmequan, and S. Russ. 2002. A new paradigm for computer-based decision support. Decision Support Systems 2 (June).

Booz-Allen \& Hamilton, Inc. 2000. Developing a regional approach to fare collection. Booz-Allen, \& Hamilton, Inc. Arlington, VA.

Buehlmann, U., C. T. Ragsdale, and B. Gfeller. 2000. A spreadsheet-based decision support system for wood panel manufacturing, Decision Support Systems 3 (October).

Casey, R., and J. Collura. 1994. Advanced public transportation systems: Evaluation guidelines. U.S. Department of Transportation. Washington, DC.

Collura, J., and V. Plotnikov. 2001. EPS evaluation. In Proceedings of the 11th ITS America Annual Meeting. Miami, FL. Intelligent Transportation Society of America, Washington, DC.

E-Squared Engineering. 2000. Introduction to electronic payment systems in transportation. Intelligent Transportation Society of America. Washington, DC.

FTA. 1997. NTD user's guide. U.S. Department of Transportation. Washington, DC.

FTA. 1998. Uniform system of accounts. U.S. Department of Transportation. Washington, DC.

FTA. 1999a. Glossary of transit terminology for NTD reporting. U.S. Department of Transportation. Washington, DC.

FTA.1999b. National Transit Database reporting manual. U.S. Department of Transportation. Washington, DC.

FTA. 2001. Ventura county fare integration. A case study. U.S. Department of Transportation. Washington, DC.

Fleishman, D., C. Schweiger, D. Lott, and G. Pierlott. 1998. TCRP report 32: Multipurpose transit payment media. National Academy Press. Washington, DC. 
Fleishman, D., N. Shaw, A. Joshi, R. Freeze, and R. Oram. 1996. TCRP report 10: Fare policies, structures, and technologies. National Academy Press. Washington, DC.

Gilcrease, E. 2000. Back office requirements" in Introduction to fare collection: Proceedings of the training seminar. Held in conjunction with the APTA Fare Collection Committee annual workshop in Crystal City, VA. March 19-23.

KPMG. 1992. Estimation of operating and maintenance costs for transit systems. U.S. Department of Transportation. Washington, DC.

Lovering, M., and D. Ashmore. 2000. Developing the business case. ITS International 1 (January/February).

V. Plotnikov. 2001. An analysis of fare collection costs on heavy rail and bus systems in the U.S., Unpublished Ph.D. dissertation, Virginia Polytechnic Institute and State University, Falls Church, VA.

Price Waterhouse. 1987. Fully allocated cost modeling. U.S. Department of Transportation. Washington, DC.

Ross, S. A., R. W. Westerfield, and J. Jaffe. 1966. Principles of finance. McGraw Hill.

Shim, J. P., M. Warkentin, J. F. Courtney, D. J. Power, R. Sharda, and C. Carlsson. 2002. Past, present, and future of decision support technology. Decision Support Systems 2 (June).

\section{About the Authors}

Parviz Ghandforoush (pghandfo@vt.edu) is professor of business information technology at Virginia Polytechnic Institute and State University. Dr. Ghandforoush has more than 25 years of research, administrative, and professional experience in information technology and management science. He has published extensively in refereed academic and professional publications in the areas of decision and optimization models, DSS in complex environments, sequencing and scheduling, staffing models, and simulation of organizational operations. Dr. Ghandforoush is director of the E-Business Systems Integration Center and managing director of the Master of Information Technology Program at Virginia Tech.

John Collura (jcollura@vt.edu<jcollura@vt.edu) has more than 25 years of experience in transportation research and education with an emphasis on public transportation planning and management and performance evaluation and the appli- 
cation of information based technologies. He also teaches courses in public transit design and operations and in public transit planning and analysis. He is a professor of civil engineering and a Transportation Fellow at the Virginia Tech Transportation Institute. Dr. Collura, a professionally registered engineer, and received his Ph.D. in civil engineering at North Carolina State University.

Valerı Plotnikov (vplotnik@vt.edu) is a research associate at the Virginia Polytechnic Institute and State University. Over the last six years, he has been actively involved in research relating to planning, design, economic, and functional evaluation of Intelligent Transportation Systems. Dr. Plotnikov is an active participant at ITS America, Smart Card Forum, Institute of Transportation Engineers (ITE), Transportation Research Board (TRB), and American Public Transportation Association (APTA) conferences and meetings. 